\title{
Outcome of off-pump coronary artery bypass graft (OPCAB) surgery: Analysis of 129 cases
}

\author{
AKM Manzurul Alam ${ }^{1}$, Istiaq Ahmed ${ }^{2}$, Manzil Ahmed ${ }^{2}$, Al Mamun Hossain ${ }^{3}$
}

\begin{abstract}
:
Coronary artery disease (CAD) is a leading cause of morbidity and mortality worldwide, including Bangladesh. Besides medical and interventional treatment, coronary artery bypass graft (CABG) surgery in an effective modality for the management of a subset of CAD patients. Off-pump coronary artery bypass graft (OPCAB) surgery is a recent modification of conventional CABG surgery, which, like other parts of the world, is being increasingly practiced in Bangladesh. But the outcome of this relatively recent surgical approach in our setting is largely unknown. In this study, the outcomes of 129 cases off-pump CABG surgery done in
\end{abstract}

a tertiary cardiovascular centre and a private institute in Dhaka were analyzed. Majority $(67,54.2 \%)$ had triple vessel disease (TVD), while 4 (3.2\%) patients had left main disease. One, two and three grafts were used in $17(13.2 \%), 74(57.4 \%)$ and $38(29.4 \%)$ cases respectively. There was no mortality. Post-operative complications occurred in $17(13.18 \%)$ patients; secondary wound infection in $10(7.75 \%)$ and immediate respiratory distress in $7(5.43 \%)$ cases. Ten $(7.75 \%)$ patients needed secondary stitches.

Key words: Coronary artery disease, Cardiac Surgery, Coronary artery bypass graft, Off-pump.

(Bangladesh Heart Journal 2016; 31(1) : 23-25)

\section{Introduction:}

Coronary artery bypass graft (CABG) operation has become the most completely studied surgical operation in the history of surgery and has been shown to be highly effective for the relief of severe angina. ${ }^{1}$ In 1962 cardiac surgeon Dr. Sabiston conducted the first unsuccessful saphenous vein graft from the ascending aorta to the distal right coronary artery and the patient died 3 day later. The technique was then pioneered in Cleveland Clinic in USA in late 1960s. First successful CABG was done by Dr. Robest. H. Goetz and his tream. ${ }^{2}$ The major development was in 1970 when internal mammary artery was used as bypass conduit to the coronary artery. By mid 1970s, may centers in USA, Australia and Europe were performing CABG with low perioperativemortality and high rate of pain relief. ${ }^{3}$

Off pump coronary artery bypass graft or beating heart surgery was primarily developed in early 1990s by Dr.

1. Professor of Cardiovascular and Thoracic Surgery, National Institute of Cardiovascular Diseases (NICVD), Dhaka.

2. Assistant Professor of Cardiovascular and Thoracic Surgery, NICVD, Dhaka.

3. Assistant Registrar of Cardiovascular and Thoracic Surgery, NICVD, Dhaka.
Amno Atsushi and it reduces the number of complications related to cardiopulmonary bypass. ${ }^{4}$

In Bangladesh CABG and off-pump CABG started towards the end of last century. In this study short-term outcome of 129 cases of off-pump CABG was observed.

\section{Method and Material:}

129 patients with coronary artery disease underwent offpump CABG during July 2013 to December 2015 in the National Institute of Cardiovascular Diseases (NICVD) and a private institute in Dhaka. After proper pre anesthetic evaluation, Off-pump CABG was done in all patients maintaining standard procedures. Octopus or fixation was used in every cases to fix up the area of operation.

Result:

Off-pump CABG was done in 129 patients with coronary artery diseases from July 2013 to December 2015. Clinical profile of the patients is shown in Table I.

Out of 129 cases undergoing OPCAB surgery, 121 were male and only 8 were female. Age ranged from 25 to 70 years and most of the patients were between the age of 40 and 70 years. (Table 2) 
Table-I

Clinical Profile of the patients undergoing off-pump CABG. $(N=129)$

\begin{tabular}{ll}
\hline Total Cases & $: 129$ \\
Male & $: 121(93 \%)$ \\
Female & $: 08(07 \%)$ \\
Mean Age & $: 51.6 \pm 8.32$ \\
Male & $: 53.6 \pm 6.7$ \\
Female & \\
Clinical History & $: 58 \%(75)$ \\
Prior MI & $: 35 \%(45)$ \\
Hypertension & $: 9.3 \%(12)$ \\
Heart Failure & $: 12.5 \%(16)$ \\
Diabetes Mellitus & \\
Cigarette Smoking & $: 29 \%$ \\
Present smoker & $: 46 \%$ \\
Ex. smoker & $: 25 \%$ \\
Non smoker & $: 80(62 \%)$ \\
Medication & $: 120(93 \%)$ \\
Long acting GTN & $: 129(100 \%)$ \\
Beta Blockers & $: 105(81 \%)$ \\
Anti-platelets &
\end{tabular}

Table-II

Distribution of patients by age and sex. $(N=129)$

\begin{tabular}{lcccc}
\hline Age range & Male & Female & Total & Percentage \\
\hline 21-30 years & 01 & 00 & 01 & 0.8 \\
31-40 years & 08 & 01 & 09 & 6.9 \\
41-50 years & 44 & 02 & 46 & 35.7 \\
51-60 years & 47 & 02 & 49 & 37.9 \\
$61-70$ years & 21 & 03 & 24 & 18.7 \\
\hline Total & 121 & 08 & 129 & \\
\hline
\end{tabular}

Left main disease was present in 4 patients and 67 had triple-vessel disease. The pattern of coronary artery disease is show in Table III.

Table-III

Pattern of coronary diseases $(N=129)$

\begin{tabular}{lcccc}
\hline Defects & Male & Female & Total & Percentage \\
\hline SVD & 09 & 03 & 12 & 9.3 \\
DVD & 41 & 02 & 43 & 33.3 \\
TVD & 67 & 03 & 70 & 54.2 \\
Left main disease & 04 & 0 & 04 & 3.2 \\
\hline Total & 121 & 08 & 129 & \\
\hline
\end{tabular}

Off pump CABG were done in all cases in standard procedures. Number of graft used are shown in Table 4.
Table-IV

Number of grafts used $(N=129)$

\begin{tabular}{lll}
\hline Single graft & 17 & $13.2 \%$ \\
Two grafts & 74 & $57.4 \%$ \\
Three grafts & 38 & $29.4 \%$ \\
\hline
\end{tabular}

There was no mortality. Post-operative complications were seen in $17(13.18 \%)$ patients. Secondary wound infection were found in $10(7.75 \%)$ cases and immediate respiratory distress were seen in $7(5.43 \%)$ cases . All the patients were managed accordingly and in 10 patients secondary stitches had to be given for proper healing of the wound. Patients were discharged with advice of regular use of anti-platelets, beta blockers and statin among others.

\section{Discussion:}

Medical and surgical therapies for patients with coronary artery diseases have changed over last 20 years. Coronary artery bypass surgery is the treatment of choice for patients who have poorly controlled angina pain after adequate medical management. Majority of the coronary surgical procedures are performed for multiple vessels diseases and overall mortality rate is also very low i.e., around $2-3 \%$.

In this series of 129 cases there was no morality though majority i.e. $52.4 \%$ had triple-vessel disease and only $9.3 \%$ patients had single vessel diseases.

Now-a-days more than $25 \%$ of CABG operations are being done as off-pump CABG. It is safe as on-pump surgery and in experienced hands offers less early complications, particularly in those patients with significant comorbidity. ${ }^{7}$

This study demonstrates the feasibility and safety of OPCAB heart surgery in Bangladesh.

\section{References:}

1. Hawkes AL, Nowak M, Bidstrup B, Speare R. Outcomes of coronary artery bypass graft surgery. Vasc Health Risk Manag. 2006;2(4):477-84. Review.

2. Konstantinov IE. Robert H. Goetz: the surgeon who performed the first successful clinical coronary artery bypass operation. Ann Thorac Surg. 2000 Jun;69(6):1966-72.

3. Pollick C. Coronary artery bypass surgery. Which patients benefit? Can Fam Physician. 1993 Feb;39:318-23.

4. Eagle KA, Guyton RA, Davidoff R, Edwards FH, Ewy GA, Gardner TJ, Hart JC, Herrmann HC, Hillis LD, 
Hutter AM Jr, Lytle BW, Marlow RA, Nugent WC, Orszulak TA; American College of Cardiology; American Heart Association. ACC/AHA 2004 guideline update for coronary artery bypass graft surgery: a report of the American College of Cardiology/American Heart Association Task Force on Practice Guidelines (Committee to Update the 1999 Guidelines for Coronary Artery Bypass Graft Surgery). Circulation. 2004 Oct 5;110(14):e340-437.

5. National Institutes of Health Consensus Development Conference statement-coronary artery bypass surgery: scientific and clinical aspects. December 3-5, 1980. J Ark Med Soc. 1983 Aug;80(3):140-6.

6. Principal Investigators of CASS and Their Associates, Killip T, Fisher LD, Mock MB; The National Heart, Lung, and Blood Institute Coronary Artery Surgery Study (CASS). Circulation 63 1981:I1-I-81. (suppl I).

7. Pepper J. Controversies in off-pump coronary artery surgery. Clin Med Res. 2005 Feb;3(1):27-33. Review. 